Supporting Information

\title{
Stabilizing the Interface of All-Solid-State Electrolytes Against Cathode Electrodes by Atomic Layer Deposition
}

\author{
Ye $\operatorname{Jin}^{a}$, Han $\mathrm{Yu}^{a}$, Xiaoqing He${ }^{b, c}$, and Xinhua Liang ${ }^{a, *}$ \\ ${ }^{a}$ Linda and Bipin Doshi Department of Chemical and Biochemical Engineering, Missouri \\ University of Science and Technology, Rolla, Missouri 65409, United States \\ ${ }^{\mathrm{b}}$ Electron Microscopy Core Facility, University of Missouri, Columbia, Missouri 65211, United \\ States \\ c Department of Mechanical and Aerospace Engineering, University of Missouri, Columbia, \\ Missouri 65211, United States \\ * Corresponding author. E-mail: liangxin@mst.edu
}


This Supporting Information file includes following data. Figure S1, Arrhenius plots of the ionic conductivity of $\mathrm{Li} /$ membranes/Li with different weight ratios of PVDF/PEO, LAGP, and LiTFSI; Figure S2, FTIR spectra of various membranes; Figure S3, Nyquist plots of the ionic conductivity of SS/ASSE/SS at different temperatures; Figure S4, Galvanostatic cycling curves of symmetrical $\mathrm{Li} / \mathrm{ASSE} / \mathrm{Li}$ cell at (a) $0.1 \mathrm{~mA} \mathrm{~cm}{ }^{-2}$ and (b) different current densities of $0.1,0.2,0.3$, and $0.5 \mathrm{~mA}$ $\mathrm{cm}^{-2}$ at room temperature; Figure S5, XPS spectra of (a) survey scan and (b) core level of Zr 3d of 10Zr-LFP powders, and (c) core level of $\mathrm{Zr} 3 \mathrm{~d}$ of fresh 2Zr-LFP electrode; Figure S6, the charge/discharge curves of the $1^{\text {st }}, 10^{\text {th }}$, and $60^{\text {th }}$ cycles of (a) LFP/ASSE/Li and (b) 2Zr$\mathrm{LFP} / \mathrm{ASSE} / \mathrm{Li}$ at $60^{\circ} \mathrm{C}$ and $0.1 \mathrm{C}$ rate with a potential range of $2.5-4.0 \mathrm{~V}$; Figure S7, (a) Cycling performance of LFP/Li cells with ASSE at $60{ }^{\circ} \mathrm{C}$ at a $0.05 \mathrm{C}$ rate and Nyquist plots of LFP/Li cells with ASSE (b) at the $0^{\text {th }}$ cycle and (c) $20^{\text {th }}$ cycle; Figure S8, Nyquist plots of (a) LFP/ASSE/Li and (b) 2Zr-LFP/ASSE/Li at different temperatures and (c) equivalent circuit; Figure S9, CV curves of (a) LFP/ASSE/Li and (b) 2Zr-LFP/ASSE/Li at different scan rates of $0.1,0.2,1.0$, and $2.0 \mathrm{mVs}^{-1}$, and (c) peak current vs. the square root of the scan rate for LFP/ASSE/Li and 2Zr-LFP/ASSE/Li; Figure S10, XPS survey scan of (a) electrodes and (b) ASSE; Figure S11, Core levels of C 1s of (a) fresh ASSE, (b) fresh LFP electrode, and (c) fresh 2Zr-LFP electrode; Figure S12, Core levels of $\mathrm{Zr} 3 \mathrm{~d}$ of (a) fresh 2Zr-LFP electrode and (b) cycled ASSE in 2Zr-LFP/ASSE/Li cell; Figure S13, Core levels of F 1s of (a) fresh LFP electrode, (b) fresh 2Zr-LFP electrode, (c) cycled LFP electrode, and (d) cycled 2Zr-LFP electrode.

Table S1, EIS fitting results of LFP and 2Zr-LFP electrodes at different temperatures; Table S2, Binding energies (BE) and atomic concentrations (at.\%) of electrodes and ASSE, identified by XPS on the surface of the electrodes and ASSE. 


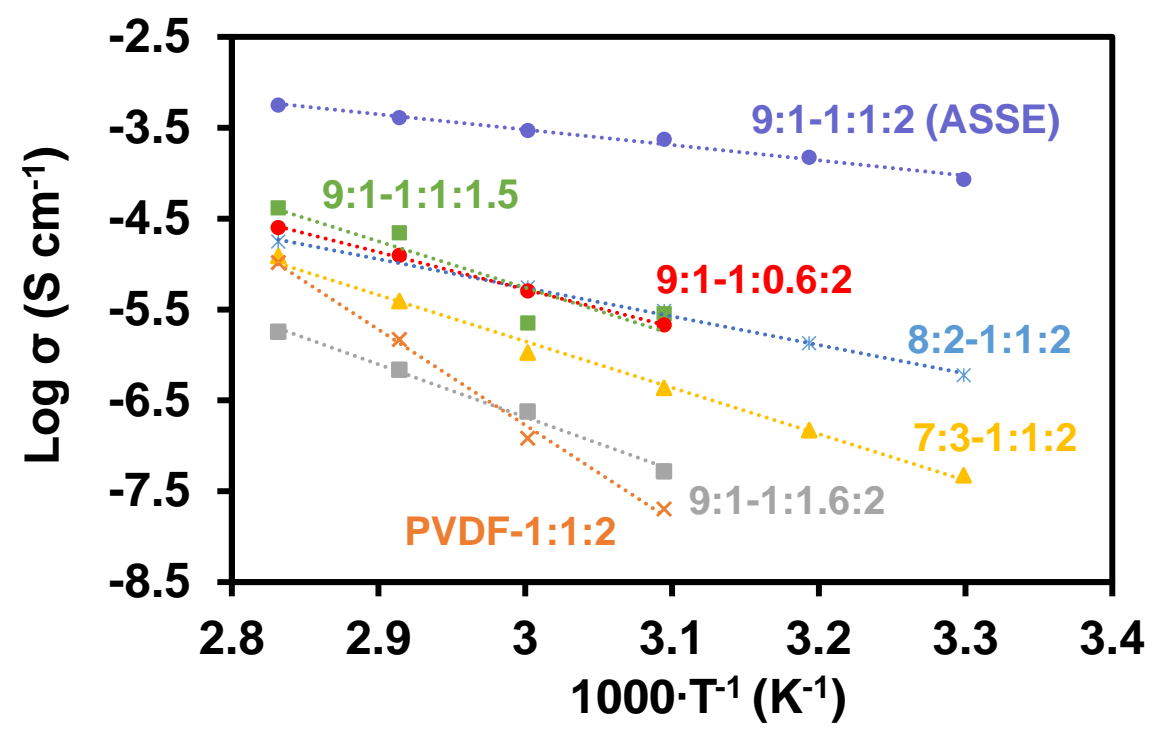

Figure S1. Arrhenius plots of the ionic conductivity of $\mathrm{Li} / \mathrm{membranes} / \mathrm{Li}$ with different weight

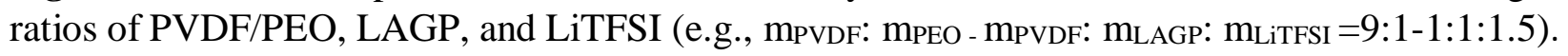

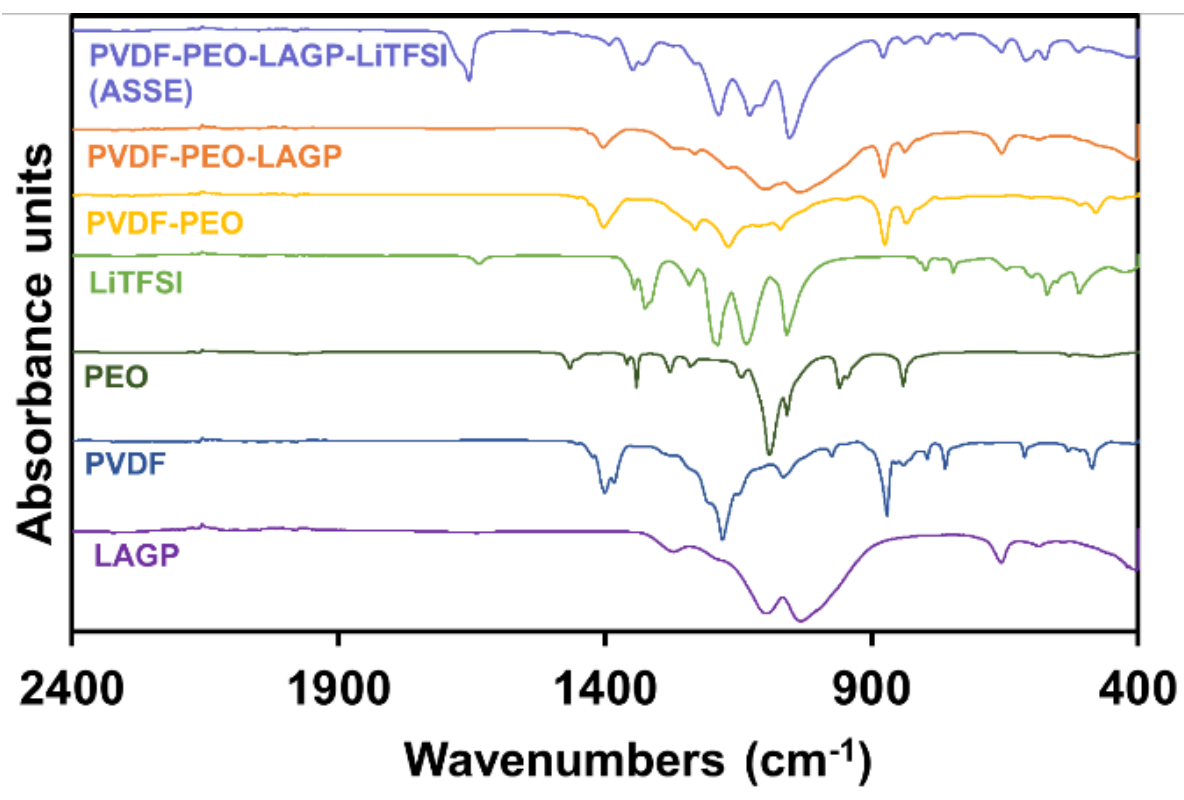

Figure S2. FTIR spectra of various membranes. 


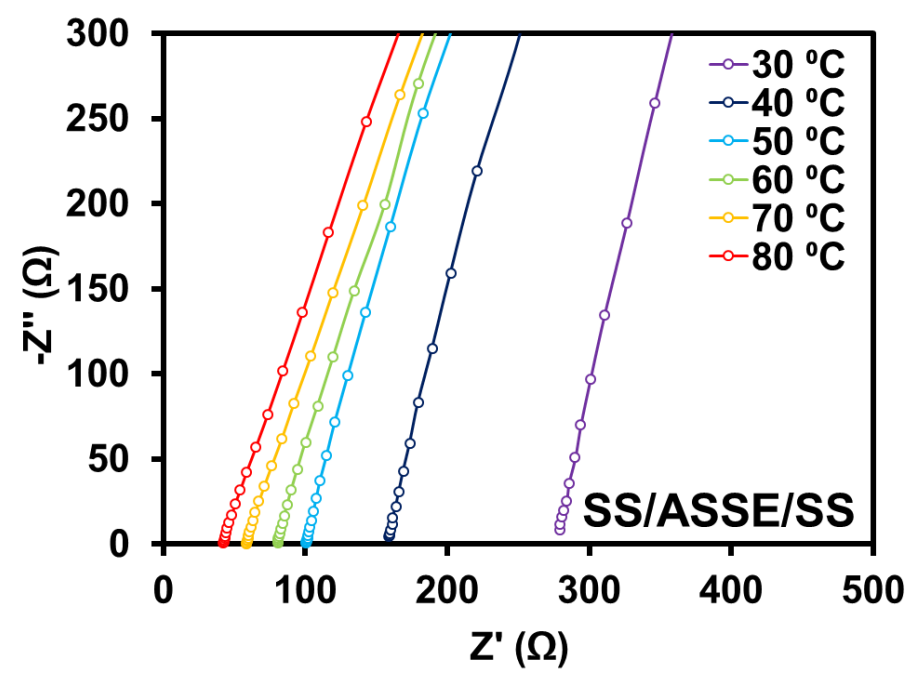

Figure S3. Nyquist plots of the ionic conductivity of SS/ASSE/SS at different temperatures.
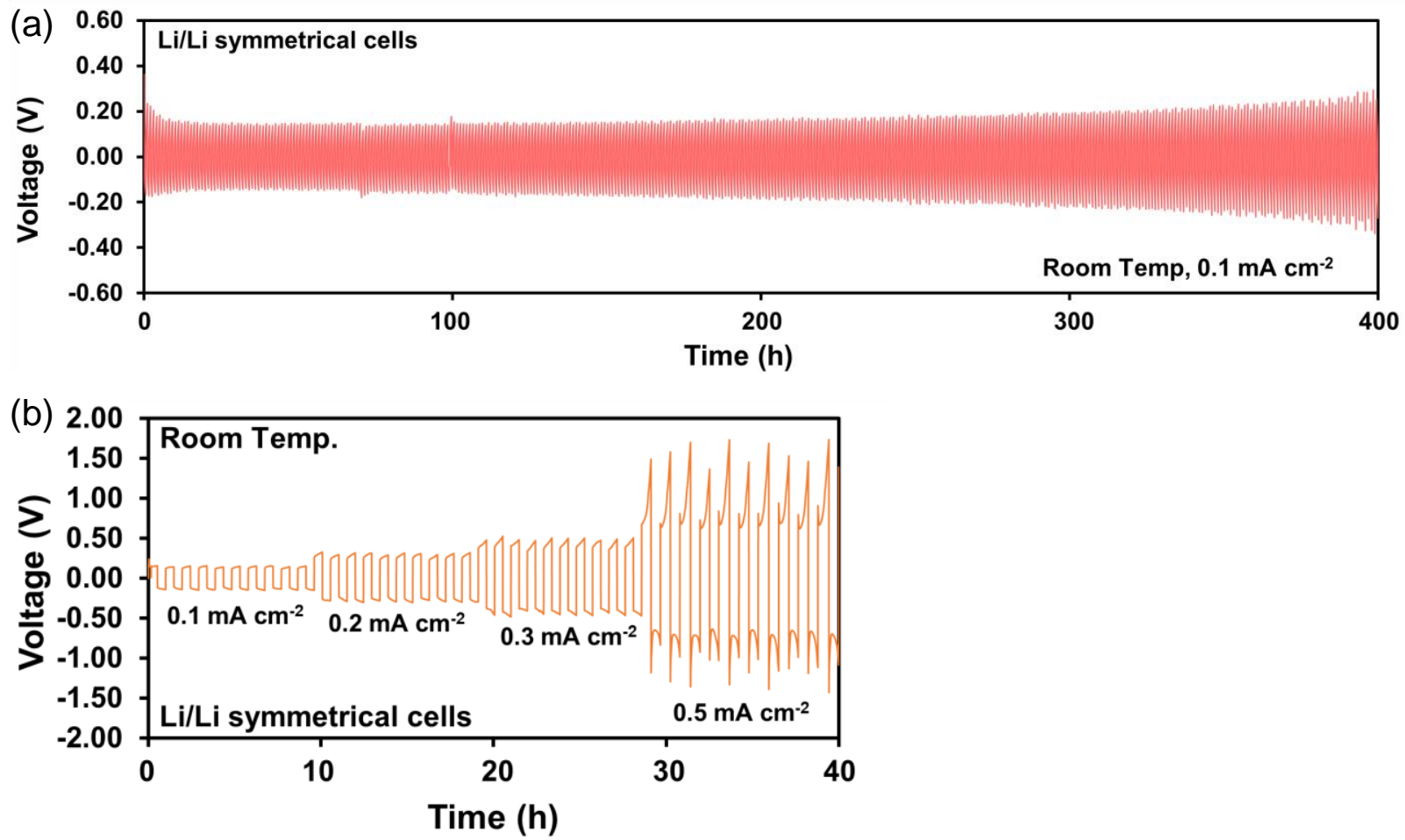

Figure S4. Galvanostatic cycling curves of symmetrical Li/ASSE/Li cell at (a) $0.1 \mathrm{~mA} \mathrm{~cm}^{-2}$ and (b) different current densities of $0.1,0.2,0.3$, and $0.5 \mathrm{~mA} \mathrm{~cm}^{-2}$ at room temperature. 

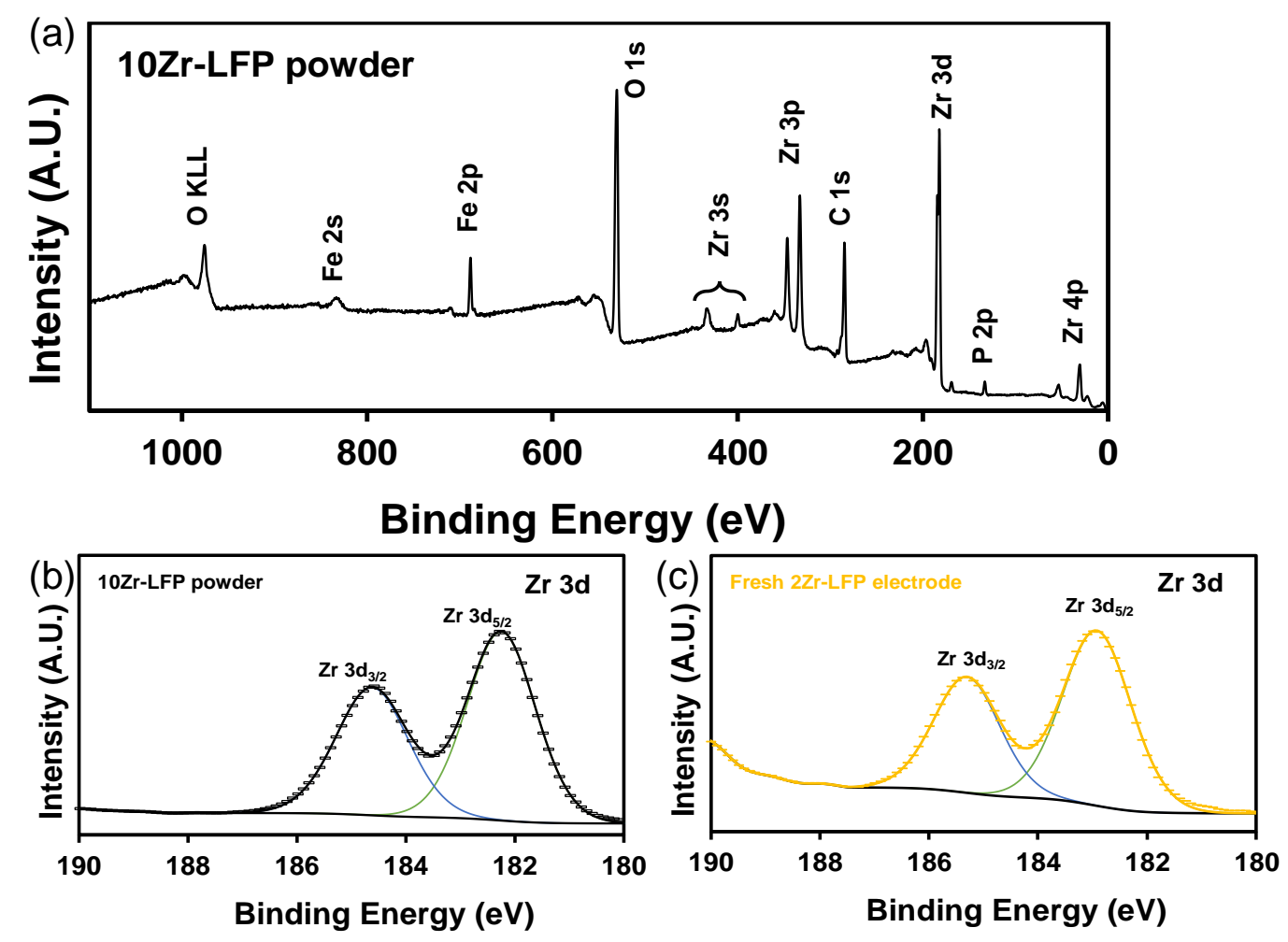

Figure S5. XPS spectra of (a) survey scan and (b) core level of Zr 3d of 10Zr-LFP powders, and (c) core level of $\mathrm{Zr} 3 \mathrm{~d}$ of fresh $2 \mathrm{Zr}$-LFP electrode.
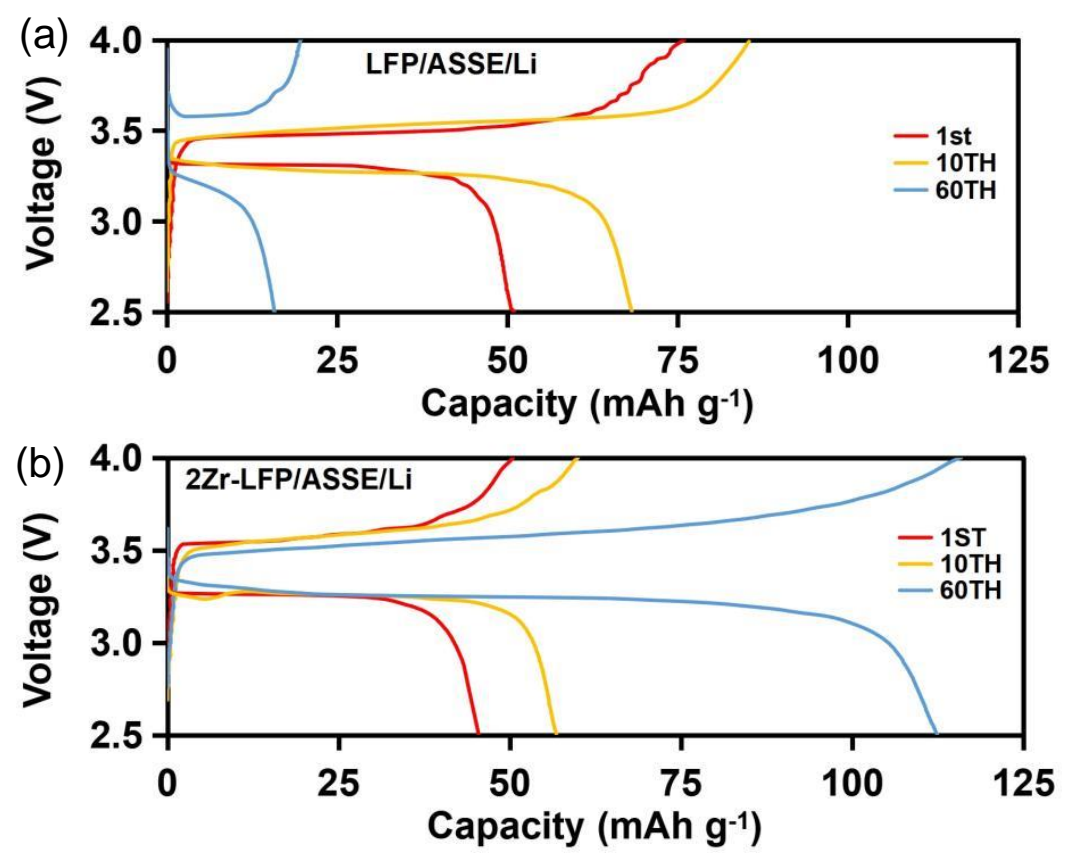

Figure S6. The charge/discharge curves of the $1^{\text {st }}, 10^{\text {th }}$, and $60^{\text {th }}$ cycles of (a) LFP/ASSE/Li and (b) $2 \mathrm{Zr}-\mathrm{LFP} / \mathrm{ASSE} / \mathrm{Li}$ at $60{ }^{\circ} \mathrm{C}$ and $0.1 \mathrm{C}$ rate with a potential range of $2.5-4.0 \mathrm{~V}$. 

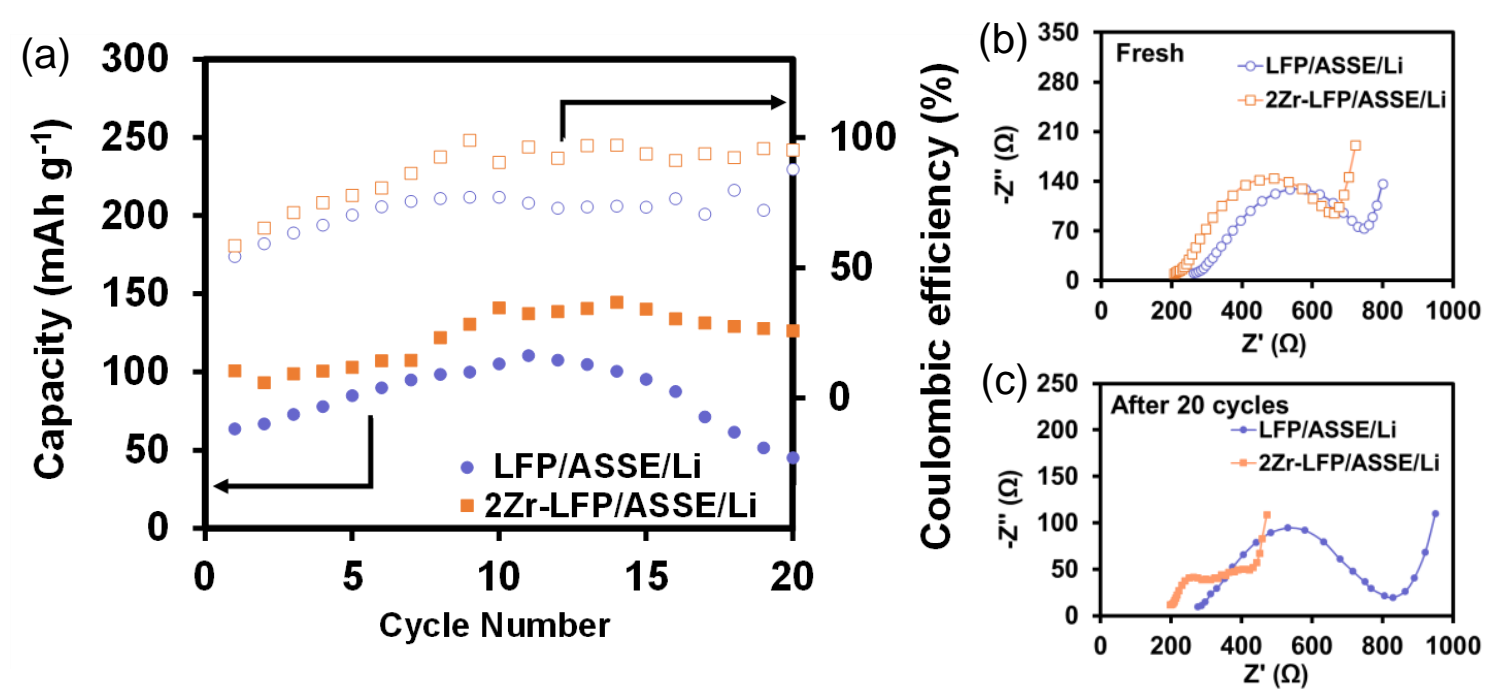

Figure S7. (a) Cycling performance of LFP/Li cells with ASSE at $60{ }^{\circ} \mathrm{C}$ at a $0.05 \mathrm{C}$ rate and Nyquist plots of LFP/Li cells with ASSE (b) at the $0^{\text {th }}$ cycle and (c) $20^{\text {th }}$ cycle.
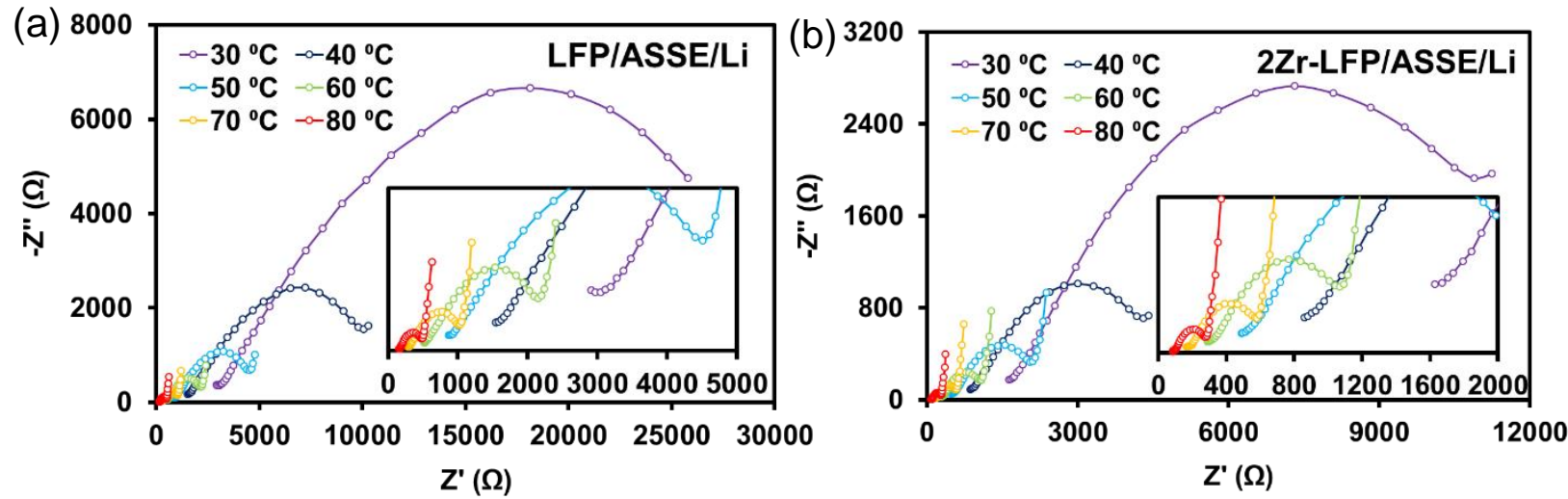

(c)

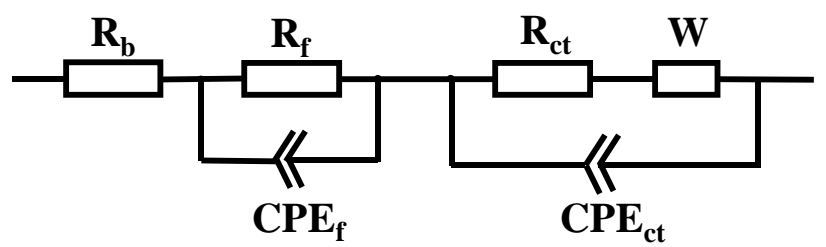

Figure S8. Nyquist plots of (a) LFP/ASSE/Li and (b) 2Zr-LFP/ASSE/Li at different temperatures, and (c) equivalent circuit. 

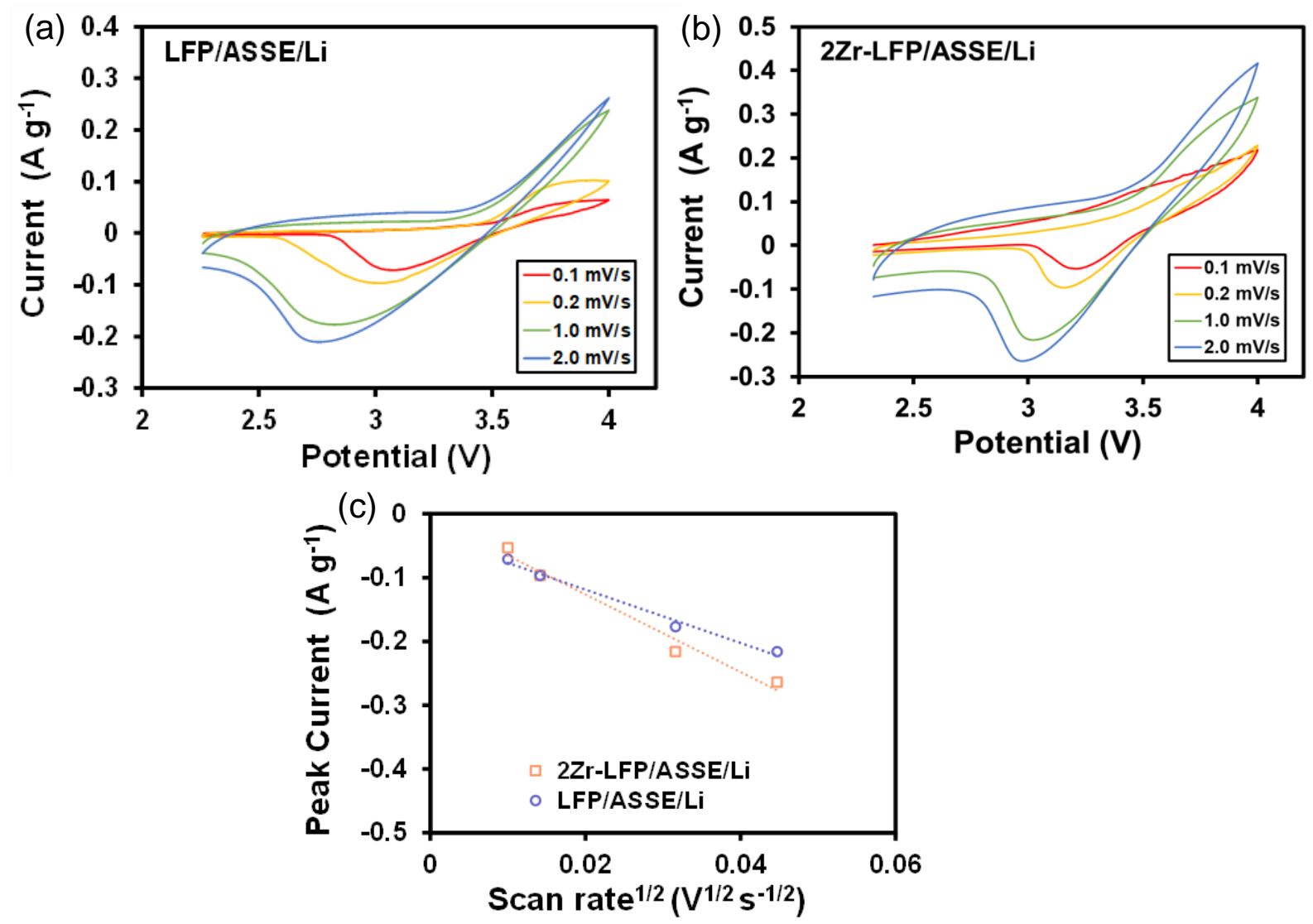

Figure S9. CV curves of (a) LFP/ASSE/Li and (b) 2Zr-LFP/ASSE/Li at different scan rates of 0.1, $0.2,1.0$, and $2.0 \mathrm{mVs}^{-1}$, and (c) peak current vs. the square root of the scan rate for LFP/ASSE/Li and $2 \mathrm{Zr}-\mathrm{LFP} / \mathrm{ASSE} / \mathrm{Li}$. 

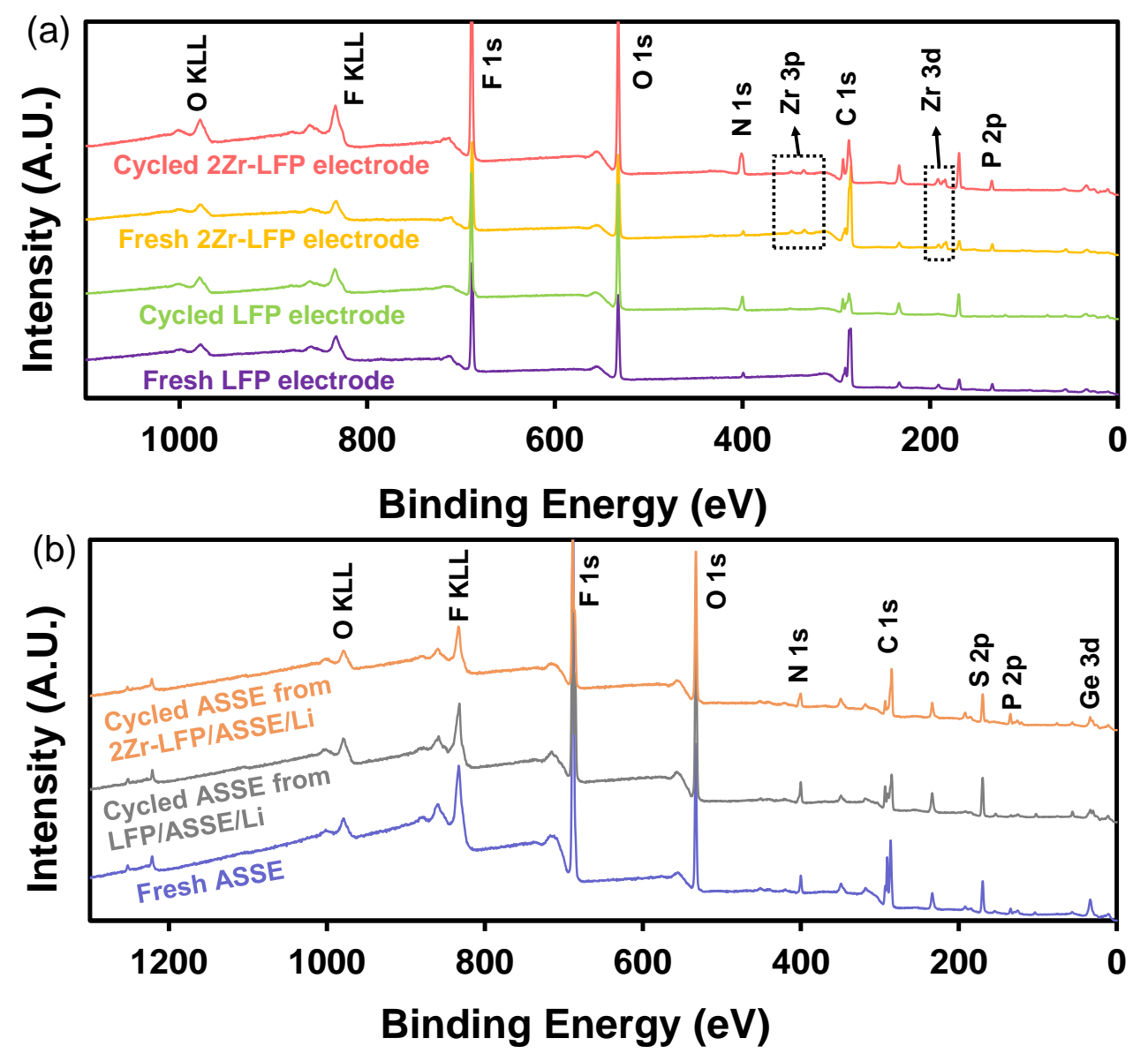

Figure S10. XPS survey scan of (a) electrodes and (b) ASSE. 

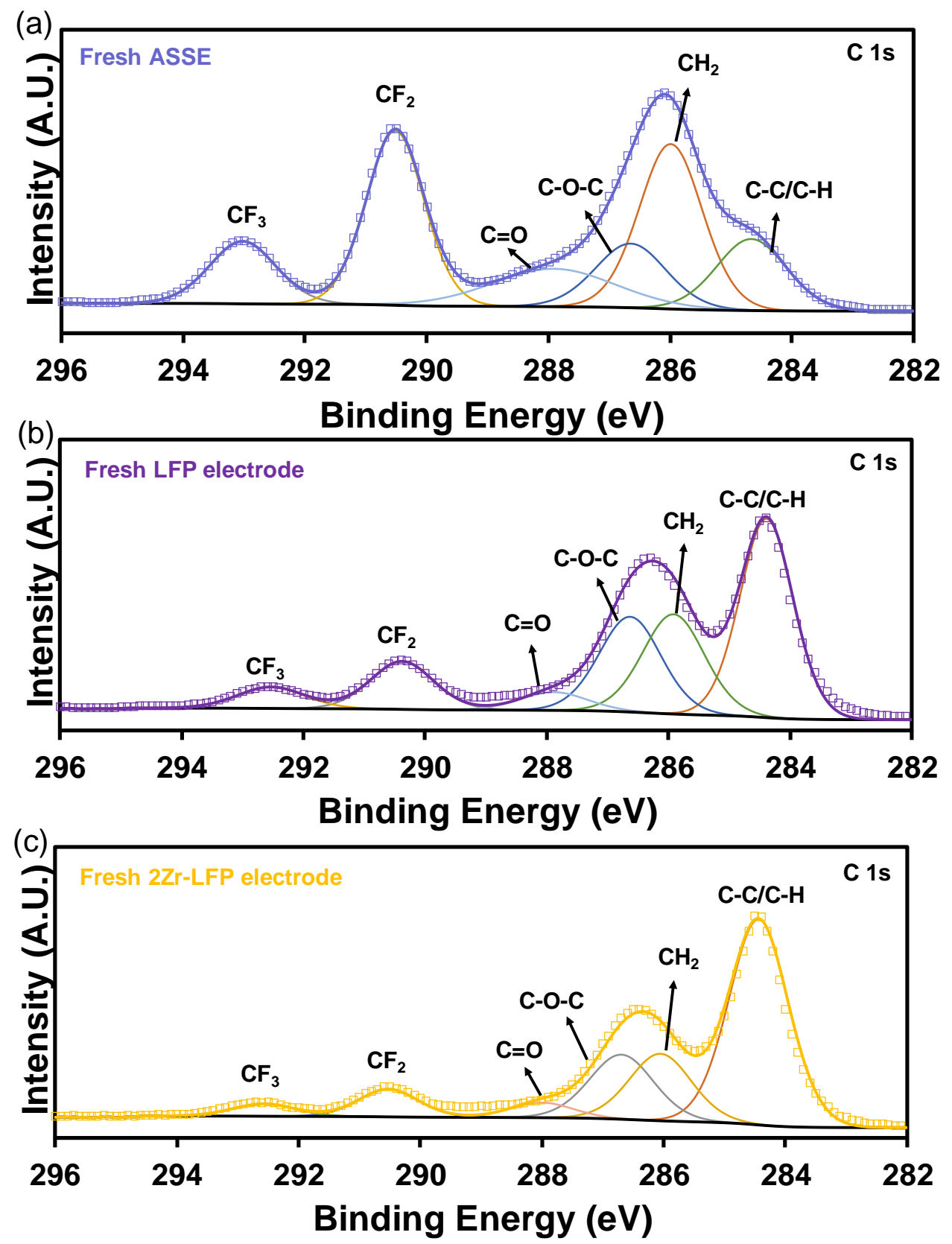

Figure S11. Core levels of C 1s of (a) fresh ASSE, (b) fresh LFP electrode, and (c) fresh 2ZrLFP electrode. 


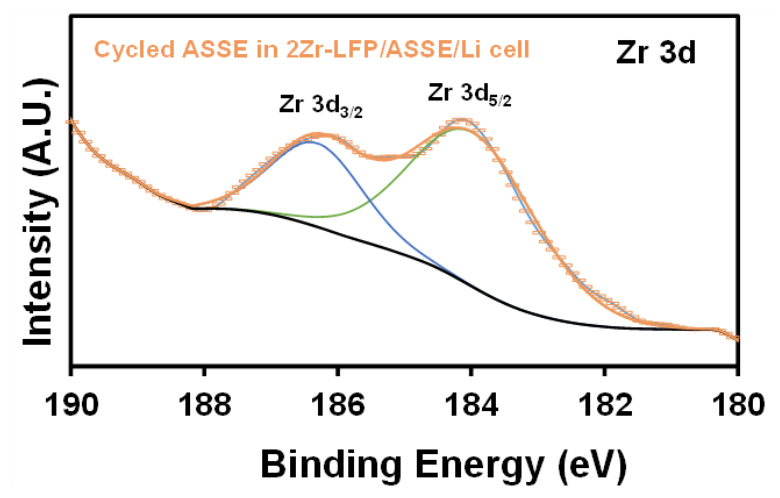

Figure S12. Core levels of Zr 3d of cycled ASSE in 2Zr-LFP/ASSE/Li cell.
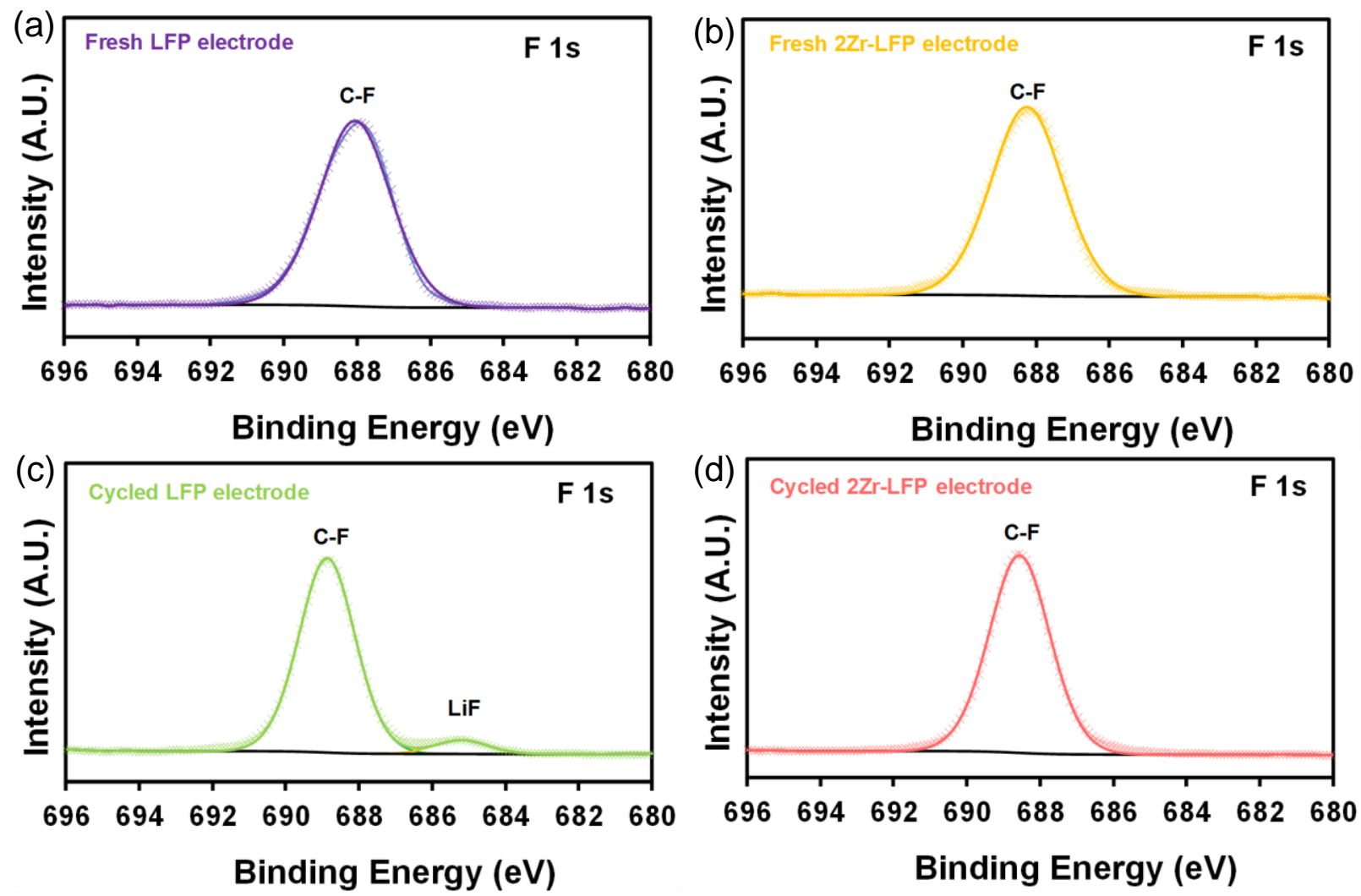

Figure S13. Core levels of F 1s of (a) fresh LFP electrode, (b) fresh 2Zr-LFP electrode, (c) cycled LFP electrode, and (d) cycled 2Zr-LFP electrode. 
Table S1. EIS fitting results of LFP and 2Zr-LFP electrodes at different temperatures.

\begin{tabular}{cccccc}
\hline Electrode & $\begin{array}{c}\text { Temp. } \\
\left({ }^{\circ} \mathrm{C}\right)\end{array}$ & $\mathrm{R}_{\mathrm{b}}(\Omega)$ & $\mathrm{R}_{\mathrm{f}}(\Omega)$ & $\mathrm{R}_{\mathrm{ct}}(\Omega)$ & Total $(\Omega)$ \\
\hline \multirow{6}{*}{ LFP } & 30 & 2791 & 27415.6 & 286.4 & 30493 \\
& 40 & 1407 & 8762.1 & 214.9 & 10384 \\
& 50 & 808.1 & 3943.3 & 96.7 & 4848.1 \\
& 60 & 506 & 1543.4 & 62.6 & 2112 \\
& 70 & 275.6 & 675.4 & 30.6 & 981.6 \\
2 Zr-LFP & 80 & 155.7 & 340.6 & 13.5 & 509.7 \\
& 30 & 1551 & 8403.5 & 176.5 & 10131 \\
& 40 & 779.1 & 3138.5 & 112.5 & 4030.1 \\
& 50 & 476.4 & 1524.0 & 63.0 & 2063.4 \\
& 70 & 276 & 863.6 & 40.4 & 1180 \\
& 80 & 173 & 473.0 & 22.0 & 668 \\
& 80 & 87.4 & 240.0 & 11.0 & 338.4 \\
\hline
\end{tabular}

Table S2. Binding energies (BE) and atomic concentrations (at.\%) of electrodes and ASSE, identified by XPS on the surface of the electrodes and ASSE.

\begin{tabular}{|c|c|c|c|c|c|c|c|c|}
\hline \multirow[b]{2}{*}{ Assignment } & \multicolumn{2}{|c|}{$\begin{array}{l}\text { Cycled LFP } \\
\text { electrode }\end{array}$} & \multicolumn{2}{|c|}{$\begin{array}{l}\text { Cycled 2Zr-LFP } \\
\text { electrode }\end{array}$} & \multicolumn{2}{|c|}{$\begin{array}{l}\text { Cycled ASSE in } \\
\text { LFP/ASSE/Li }\end{array}$} & \multicolumn{2}{|c|}{$\begin{array}{l}\text { Cycled ASSE in } \\
\text { 2Zr-LFP/ASSE/Li }\end{array}$} \\
\hline & $\mathrm{BE}(\mathrm{eV})$ & at. $\%$ & $\mathrm{BE}(\mathrm{eV})$ & at. $\%$ & $\mathrm{BE}(\mathrm{eV})$ & at. $\%$ & $\mathrm{BE}(\mathrm{eV})$ & at. $\%$ \\
\hline $\mathrm{C}-\mathrm{C} / \mathrm{C}-\mathrm{H}$ & 284.7 & 16.1 & 284.8 & 19.6 & 284.7 & 35.3 & 284.7 & 51.1 \\
\hline$-\mathrm{CH}_{2}$ & 286.3 & 23.2 & 286.6 & 25.7 & 286.5 & 13.0 & 286.1 & 15.3 \\
\hline $\mathrm{C}-\mathrm{O}-\mathrm{C}$ & 286.9 & 13.0 & 287.2 & 18.8 & 287.1 & 9.5 & 287.0 & 13.9 \\
\hline $\mathrm{C}=\mathrm{O}$ & 288.5 & 11.7 & 288.7 & 9.5 & 288.9 & 8.2 & 288.6 & 4.9 \\
\hline$-\mathrm{CO}_{3}$ & 289.3 & 6.4 & & & & & & \\
\hline$-\mathrm{CF}_{2}$ & 290.2 & 8.8 & 290.6 & 6.5 & 290.2 & 13.3 & 290.6 & 5.5 \\
\hline$-\mathrm{CF}_{3}$ & 292.9 & 20.7 & 293.0 & 19.9 & 293.2 & 20.7 & 293.0 & 9.3 \\
\hline
\end{tabular}

